\title{
Editorial to the FERE Special Issue "Nonthermal Technologies for Food Preservation" Based on the 2015 International Nonthermal Processing Workshop
}

\author{
Petros Taoukis $^{1} \cdot$ Magdalini Krokida $^{1} \cdot$ George Katsaros $^{2}$
}

Published online: 31 August 2017

(C) Springer Science+Business Media, LLC 2017

The International Nonthermal Processing of Food Workshop is a yearly event organized by the Nonthermal Processing Division of the Institute of Food Technologists (IFT) and the European Federation of Food Science and Technology (EFFoST).

The 2015 International Nonthermal Processing Workshop (www.npdworkshop2015.org) with the theme "Sustainable Innovation Based on Science and Applied Research of Nonthermal Technologies" took place in Athens, Greece, on November 12-13, 2015, and it was organized by the Laboratory of Food Chemistry and Technology, School of Chemical Engineering, National Technical University of Athens (NTUA).

The main objective of the workshop was the exchange of state-of-the-art knowledge on nonthermal processing to foster sound advances in the field, either on fundamentals or applications, towards innovations in a sustainable framework.
Speakers of review presentations at the workshop were invited by the Scientific Committee to submit full manuscripts to be considered for inclusion in this Food Engineering Review Special Issue. The submitted papers underwent the regular peer review process followed by this journal.

We thank the authors and the reviewers for their contributions to make this special issue of relevance and great quality and we sincerely hope this excellent collection of articles on Nonthermal Processing of Food will be well received by those working in this area and beyond.
The Guest Editors
Prof. Petros Taoukis
Prof. Magdalini Krokida
Dr. George Katsaros

Petros Taoukis

taoukis@ chemeng.ntua.gr

1 School of Chemical Engineering, National Technical University of Athens, Athens, Greece

2 Hellenic Agricultural Organisation-DEMETER, Athens, Greece 